\section{Different class}

Shaun Sellars continues this essential series on ethical dilemmas in dentistry which appears in every second issue of the BDJ.

The Sewell report from the Commission into Race and Ethnic Diversities was recently published. ${ }^{1}$ It has been both praised as a courageous, optimistic view of Britain as a welcoming society and labelled an example of policy-based evidence-making which gaslights and whitewashes the experiences of ethnic minorities throughout the country.,3 Perhaps most tellingly, from a healthcare perspective, is a $B M J$ piece intricately detailing several factual errors in the report's discussion of race-related health disparities. ${ }^{4}$

The report also highlights the complex relationship between class and racial and ethnic background, claiming that class and poverty are more important than heritage in determining people's prospects in life. The white working-class are singled out and are often used as a touchstone when discussing social mobility. ${ }^{5}$

Dentistry in the UK has a history of being a white, mostly male, middle-class profession. While this has changed over recent years, the upper echelons of dentistry predominantly fall into this stereotype. Given the current discussions regarding diversity in dentistry, to which I have contributed, it is clear we should also be paying more attention to these class issues.

I was born and raised into a white, workingclass family in the rural county of Lincolnshire. My route through dental school was supported by the then government policy of maintenance grants and paid tuition fees. I was the first member of my immediate family to go to university, and my VT salary of around $£ 28,000$ at the time seemed like a king's ransom. While I wasn't the only working-class person at dental school, it was clear that most entrants had come from middle-class backgrounds and many were privately educated.

What difference does your social upbringing make to the way you perceive dentistry? Speaking to friends who work in areas of high social deprivation, it's clear to see that a cohort of their patients has to make difficult decisions around their dentistry. For some patients, the difference between Band 1 and

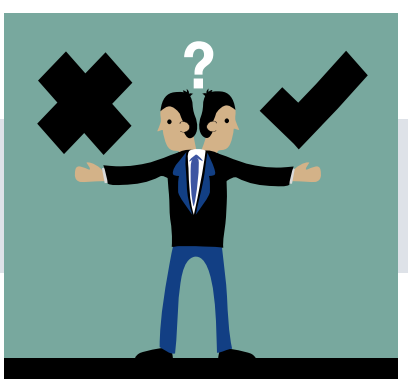

Band 2 NHS charges means choosing between having the dentistry they need or putting food on the table. The vast majority of entrants into dental school won't have had this experience and may be unable to relate to this level of deprivation, leading to knock-on effects on patient relationships and treatment.

I may have entered dental school as working-class, but it's not an accurate description of myself or many other members of the profession now. Whether we like it or not, we are de facto middle-class. And as a white male, I now have a reasonably easy route through the profession, largely unaffected by discrimination. My working-class upbringing acted as a bottleneck rather than a barrier to entry into dentistry. This can't be said for traits such as race, gender and ethnicity. Perhaps what's really important is how class interacts with these other attributes to modify the discrimination we already see.

Once again, we can see that having a diverse profession, and understanding how that diversity benefits the profession, also benefits patients.

\section{References}

1. Commission on Race and Ethnic Disparities. Commission on Race and Ethnic Disparities: The Report. 2021. Available at https://assets.publishing service.gov.uk/government/uploads/system/uploads/ attachment data/file/974507/20210331 _ CRED Report_-_FINAL_-_Web_Accessible.pdf (accessed April 2021).

2. Tombs R. The race report critics are guilty of gaslighting. The Spectator 2021. Available at https://www. spectator.co.uk/article/tony-sewell-s-race-reportcritics-are-guilty-of-gaslighting (accessed April 2021).

3. Editorial. The Observer view on the Sewell commission's race report. The Observer 2021. Available at https:// www.theguardian.com/commentisfree/2021/apr/04/ the-observer-view-on-the-sewell-commissions-racereport (accessed April 2021).

4. Razai M, Majeed A, Esmail A. Structural racism is a fundamental cause and driver of ethnic disparities in health. BMJ 2021 Available at https://blogs.bmj.com/ bmj/2021/03/31/structural-racism-is-a-fundamentalcause-and-driver-of-ethnic-disparities-in-health/ (accessed April 2021).

5. Ehsan R. White working class kids are being left behind - we need to be honest about why. CapX 2021. Available from: https://capx.co/white-working-classkids-are-being-left-behind-we-need-to-be-honestabout-why/ (accessed April 2021).

Spotlight on Evidence-Based

\title{
Dentistry
}

Part of the BDJ Portfolio, Evidence-Based Dentistry $(E B D)$ publishes invited commentaries and systematic reviews and aims to create a dialogue between dental

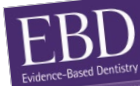

practitioners and dental researchers, in order to drive new research and promote the use of the best available evidence to inform clinical decision making.

$E B D$ is published quarterly, both online and bound into the $B D J$ itself.

Professor Elizabeth Kay has been Editor of $E B D$ since summer 2019, the successor to Professor Derek Richards who was Editor for 20 years.

\section{January highlights}

The most recent issue of $E B D$ concentrated on identifying and examining the links between lifestyle, and systemic and oral disease. Content included commentaries on:

- How strong is the link between periodontitis and stroke? https://www. nature.com/articles/s41432-021-0161-7

- Are different pulp treatment techniques and associated medicaments effective for the treatment of extensive decay in primary teeth? https://www.nature.com/articles/ s41432-021-0162-6

- Could optimising periodontal health in expectant mothers reduce the risk of babies being born prematurely? https://www. nature.com/articles/s41432-021-0149-3

- Is there an association between multiple sclerosis and oral health? https://www. nature.com/articles/s41432-021-0159-1

- What is the evidence of outcomes of endodontically treated cracked teeth? https://www.nature.com/articles/ s41432-021-0153-7.

To view the complete issue visit https:// www.nature.com/ebd/volumes/22/issues/1.

In January 2021, EBD began accepting submissions of systematic reviews. For more information please visit https://www.nature. com/ebd/for-authors. 